\title{
O DEVER DE INVESTIGAR, JULGAR E PUNIR GRAVES VIOLAÇÕES DE DIREITOS HUMANOS EM SITUAÇÕES PÓS-CONFLITO: A JUSTIÇA DE TRANSIÇÃO NA COLÔMBIA À LUZ DO SISTEMA INTERAMERICANO DE DIREITOS HUMANOS
}

\author{
THE DUTY TO INVESTIGATE, PROSECUTE AND PUNISH GROSS VIOLATIONS \\ OF HUMAN RIGHTS IN POST-CONFLICT CONTEXTS: TRANSITIONAL \\ JUSTICE IN COLOMBIA IN LIGHT OF THE INTER-AMERICAN SYSTEM OF \\ HUMAN RIGHTS
}

${ }^{1}$ Thaís Guedes Alcoforado de Moraes

\begin{abstract}
RESUMO
O dever de investigar, processar e punir graves violações de direitos humanos deriva da Convenção Americana de Direitos Humanos. O escopo e o conteúdo de tal dever foi parcialmente estabelecido pela jurisprudência da Corte Interamericana de Direitos Humanos, em casos de transição entre regimes autoritários e democráticos. Contudo, debates persistem sobre o conteúdo de tal obrigação em contextos de acordos de paz entre o Estado e grupos armados não estatais objetivando uma transição entre uma situação de conflito e a paz especialmente quanto à concessão de anistias. Este trabalho pretende elucidar o mencionado debate a partir da situação Colômbia.
\end{abstract}

Palavras-chave: Justiça de transição, Anistia, Conflito armado interno

\begin{abstract}
The duty to investigate, prosecute and punish gross violations of human rights can be deducted from the American Convention of Human Rights. The scope and content of this duty has been partially determined by the case law of the Inter-American Court of Human Rights, in cases of transition from authoritarian to democratic regimes. Nevertheless, debates on the content of this duty in contexts of peace agreeements between the State and non-state armed groups aiming at a transition from conflict to peace - especially regarding the granting of amnesty. This paper intends to illustrate this debate with the Colombia situation.
\end{abstract}

Keywords: Transitional justice, Amnesty, Internal armed conflict

\footnotetext{
${ }^{1}$ Mestranda em Direito pela Universidade de Brasília - UnB, Distrito Federal (Brasil).

E-mail: thais.alcoforado@gmail.com
} 


\section{Introdução}

A justiça de transição pode ser definida como "a concepção de justiça em períodos de transição política" (LEEBAW, 2008) ou ainda como o conjunto de estratégias judiciais e não-judiciais implementadas após um período de conflito ou violação sistemática dos direitos humanos, com vistas a confrontar o legado de abusos e construir uma paz sustentável (VAN ZYL, 2011).

Não se trata de um conceito recente, uma vez que há autores que consideram que as restaurações da democracia em Atenas entre 404 e 411 A.C. configurariam casos de justiça transicional. Contemporaneamente, debates em torno da justiça de transição foram fortemente influenciados pelas respostas jurídicas ao Nazismo, no contexto pósSegunda Guerra Mundial. Contudo, o desenvolvimento de literatura comparada sobre justiça de transição ganhou impulso a partir da "terceira onda" de transições para a democracia na América Latina e no Leste Europeu (LEEBAW, 2008).

A questão fundamental que se impunha nesse contexto era: como devem se comportar os novos líderes frente à violência política sistemática ocorrida em um regime anterior? Nos anos 1980 e 1990, o foco dos debates sobre justiça de transição era o papel de processos e expurgos administrativos em transições democráticas. No contexto da transição argentina em 1984 e chilena em 1990, os regimes recémestabelecidos se questionavam sobre punir ou perdoar as violações de direitos humanos do regime anterior. Comissões da Verdade foram desenvolvidas tanto no Chile quanto na Argentina como formas alternativas de responsabilização (LEEBAW, 2008).

Embora tais comissões não satisfizessem o que defensores de direitos humanos cunharam de "dever de processar" violações de direitos humanos de um regime predecessor, as comissões da verdade investigavam e condenavam as violações conforme parâmetros de Direito Internacional de Direitos Humanos, que estavam e estão continuamente em evolução (LEEBAW, 2008).

Quanto a tais parâmetros, o dever estatal de investigar, processar e punir graves violações de direitos humanos em contextos de transição pode ser extraído da Convenção Americana de Direitos Humanos (CADH), especialmente em seus artigos $1^{\circ}, 2^{\circ}, 8^{\circ}$ e 25 . O escopo e o conteúdo desse dever foi parcialmente estabelecido pela jurisprudência da Corte Interamericana de Direitos Humanos (Corte IDH). Há de se observar, contudo, que a maioria dos casos julgados pela Corte IDH abordavam contextos de transição de um regime autoritário para um democrático. 
Nesse sentido, debates persistem sobre o conteúdo de tal obrigação em contextos de acordos de paz entre o Estado e grupos armados não estatais objetivando uma transição de uma situação de conflito armado interno para a paz - no tocante, por exemplo, à possibilidade da concessão de anistias.

Diante disso, este trabalho buscará examinar, a partir de uma análise dos parâmetros desenvolvidos pelo Sistema Interamericano de Direitos Humanos (SIDH), se, e sob que condições, a concessão de anistias e medidas similares de 'perdão' pode ser compatibilizada com o dever de investigar, processar e punir graves violações de direitos humanos, com foco em casos de transição entre períodos de conflito armado interno e paz. A metodologia será revisão bibliográfica e jurisprudencial dos parâmetros do SIDH.

Um dos casos mais ilustrativos na região seria a Colômbia, que atualmente recentemente adotou um acordo com as Forças Armadas Revolucionárias da Colômbia (FARC), prevendo o estabelecimento de justiça de transição, após um conflito armado interno de mais de seis décadas, que apesar das negociações, perdura nos dias de hoje (INTERNATIONAL CRISIS GROUP, 2015).

À luz do exposto, este artigo estruturar-se-á da seguinte maneira: primeiramente, trará uma breve discussão teórica sobre a temática da justiça de transição, sua relação com os direitos humanos e com a busca pela construção da paz; posteriormente, apresentará os principais entendimentos do SIDH quanto à justiça de transição; finalmente, trará breves considerações sobre as questões em aberto que ainda persistem no tocante à transição do conflito para a paz sob um prisma de direitos humanos, a partir inclusive do exemplo da Colômbia.

\section{Justiça de transição, direitos humanos e a construção da paz}

"Justiça de transição" tornou-se um termo bem estabelecido no campo dos direitos humanos. Nas últimas duas décadas, o campo teórico e a prática de justiça de transição se expandiram de forma a abranger a instituição de tribunais penais internacionais (tanto cortes híbridas quanto o Tribunal Penal Internacional - TPI), o desenvolvimento de um "direito à verdade" e um "direito à reparação" no Direito Internacional, a proliferação transnacional de comissões da verdade e de reconciliação e o nascimento de ONGs dedicadas ao tema (NAGY, 2008). Entre os objetivos da justiça transicional, estão: processar os perpetradores, revelar a verdade sobre crimes passados, fornecer reparações às vítimas, reformar as 
instituições perpetradoras de abuso e promover a reconciliação. Dessa forma, a justiça de transição exige um conjunto abrangente de estratégias para enfrentar o passado bem como para olhar o futuro, evitando o reaparecimento do conflito e das violações. Considerando que, com frequência, as estratégias da justiça transicional são arquitetadas em contextos nos quais a paz é frágil ou os perpetradores conservam um poder real, deve-se equilibrar cuidadosamente as exigências da justiça e a realidade do que pode ser efetuado a curto, médio e longo prazo (VAN ZYL, 2011).

Quando, em 1994, Madeleine Albright, então Embaixadora estadunidense para as Nações Unidas, proferiu um discurso defendendo que a determinação da verdade sobre o que ocorrera na Bósnia era essencial (e não um obstáculo) para a reconciliação, tal afirmação era controversa. Afinal, a promoção da justiça de transição para apoiar reconciliação nacional foi historicamente vista como uma ameaça à reconciliação. Considerando que as comissões da verdade e tribunais penais investigam histórias extremamente violentas e sectárias, tais instrumentos foram frequentemente vistos como obstáculos para a reconciliação. Contudo, Leebaw defende que hoje a ideia de que, para atingir uma paz duradoura, os Estados devem lidar com a violência passada é amplamente reconhecida (LEEBAW, 2008).

De Baets afirma que, entre 1990 e 2006, o “direito à verdade" gradualmente emergiu. Primeiramente formulado na década de 1970, tal direito estabelece que todas as pessoas têm o direito de saber sobre abusos passados de direitos humanos: sobreviventes e parentes de vítimas em primeiro lugar, mas também outros indivíduos e, ainda mais importante, a sociedade em geral. É, portanto, um direito tanto individual (para obter alguma forma de reparação) quanto coletivo (para prevenir a ocorrência dos mesmos abusos no futuro e para conquistar acesso à informação, essencial para uma democracia sustentável) (DE BAETS, 2009).

Apesar da crescente aceitação da justiça de transição no campo dos direitos humanos, faz-se necessário ter ciência das limitações dos mecanismos que buscam estabelecer a verdade sobre abusos de direitos humanos e reparar as violações sofridas pelas vítimas. Nesse sentido, De Baets aponta que o Direito Internacional dos Direitos Humanos apresenta um potencial limitado para lidar com injustiças históricas de um passado remoto. Por outro lado, oferece diversas possibilidades para abordar injustiças históricas recentes (DE BAETS, 2009).

Ademais, embora a justiça de transição busque reparar injustiças, em face de restrições políticas, de recursos e de tempo, tal objetivo acaba se tornando um processo 
seletivo. Portanto, a justiça de transição envolve uma narração delimitada sobre a violência e sobre as possíveis soluções (NAGY, 2008). Isso suscita questionamentos sobre quais critérios devem ser utilizados para selecionar a quem, como e a que período as medidas de justiça de transição são aplicáveis.

Nesse sentido, ao abordar estratégias de priorização para o processamento de casos de grave violação aos direitos humanos na Colômbia, a Comissão Interamericana de Direitos já declarou que "considera preocupante o conceito de seletividade e a possibilidade contemplada de renunciar à investigação e processamento de graves violações aos direitos humanos, pois seriam incompatíveis com as obrigações do Estado" (COMISSÃO INTERAMERICANA DE DIREITOS HUMANOS, 2013).

A justiça de transição também sugere um período fixo de interregno com um fim determinado, conectando um passado violento e repressivo com um futuro de paz e democracia (NAGY, 2008). Como bem explica Nagy:

O 'quando' da justiça de transição está relacionado à própria concepção de transição. Seja uma transição do autoritarismo para a democracia ou da guerra para a paz (para a democracia), a justiça de transição tipicamente aparece apenas quando a violência massiva direta atingiu uma pausa. Em parte, esta aparição tem a ver com a ênfase da literatura no processamento, verdade, reparação, reconciliação e reforma, e menos em acordos de paz, administração de transição, desmobilização e reintegração (NAGY, 2008).

Tal situação traz o questionamento sobre a possibilidade de se estabelecer justiça de transição em um momento no qual a violência ainda não terminou. Em Uganda, por exemplo, Nagy indica que líderes no norte do país se opunham às ações do TPI por receio de que isso prejudicasse as negociações de paz (NAGY, 2008).

De acordo com Van Zyl, é surpreendente que se tenha dedicado tão pouca análise à interseção entre a justiça transicional e a construção da paz pós-conflito. $\mathrm{O}$ autor considera importante aceitar a existência de tensões entre paz e justiça no curto prazo e que em alguns casos difíceis é prudente e justificável adiar as demandas da justiça visando obter o término das hostilidades ou a transição a uma ordem democrática. No entanto, na visão do autor, medidas de justiça não devem ser adiadas indefinidamente, não apenas pelo efeito nocivo que isso poderia ter para a construção de uma paz sustentável, mas também porque fazê-lo significaria aumentar a grave injustiça que as vítimas já sofreram (VAN ZYL, 2011).

Dessa maneira, Van Zyl conclui que as estratégias da justiça transicional devem fazer parte integral de qualquer esforço por construir uma paz sustentável, mas em 
algumas circunstâncias, é possível que a paz e a justiça não sejam completamente compatíveis em curto prazo (VAN ZYL, 2011).

Nesse contexto, Clark e Palmer apresentam o seguinte questionamento:

Os processos de justiça são fins em si mesmos ou meios para fins mais nobres? Podemos prever os efeitos que a justiça trará? Deve a justiça ter precedência sobre outros objetivos, como estabilidade, paz, cura, perdão, desenvolvimento econômico ou reconciliação? (CLARK; PALMER, 2016).

Os mencionados autores respondem a esse questionamento criticando um sintoma da teoria de justiça de transição, qual seja, uma tendência a debates binários, como por exemplo: paz vs. justiça, punição vs. reconciliação, justiça retributiva vs. restaurativa, direito vs. política etc (CLARK; PALMER, 2016).

Ao analisar a relação entre Direito Internacional Humanitário (DIH) e justiça de transição, Salmón argumenta que a obrigação de cumprir as normas sancionadoras de DIH poderia ser vista como um obstáculo ao processo transicional, na medida em que os grupos que ainda retêm cotas de poder veem na aplicação destas normas uma razão para não ceder ao processo reconciliatório (SALMÓN, 2011).

Como resposta a isto, vários Estados latinoamericanos promulgaram as denominadas leis de autoanistia que se constituíram em sinônimo de impunidade, ou as próprias comissões da verdade que, se chegaram a alcançar o objetivo de elucidar os fatos, nem sempre asseguraram a consecução da justiça e da reconciliação. Precisamente, estes são os dois mecanismos mais utilizados na região e sua análise gera elementos para elucidar a relação do DIH com as tentativas de reconciliação nestes países, ao se examinar, por exemplo, como as comissões de verdade o usam para descobrir juridicamente as realidades que investigam, ou sua presença como fator limitante para o outorgamento de anistias (SALMÓN, 2011).

A seguir, analisar-se-ão alguns parâmetros estabelecidos pelo SIDH quanto ao tema da justiça de transição, com destaque para o tema das anistias e perdões. Avaliarse-ão também algumas questões em aberto quanto a transições do conflito para a paz.

\section{A jurisprudência do Sistema Interamericano de Direitos Humanos quanto à justiça de transição: o dever de investigar, julgar e sancionar as graves violações de direitos humanos}

O SIDH, no qual se incluem a Comissão (CIDH) e a Corte Interamericana de Direitos Humanos (Corte IDH), surgiu no contexto da evolução pós-guerra do direito internacional e em complementariedade lógica, temporal e jurídica à construção do 
sistema universal de proteção que começou a ser erguido com a Declaração da ONU de 1948 (PASQUALUCCI, 2013).

A Corte IDH foi estabelecida em 1979, momento no qual o continente americano estava tomado por diversos regimes ditatoriais. Nesse contexto, a Corte exerceu uma função primordialmente consultiva, já que o contexto político não favorecia a condenação dos Estados por violações de direitos humanos. A partir das redemocratizações, o SIDH vem se debruçando e desenvolvendo parâmetros sobre a temática da justiça de transição. Tais parâmetros são importantes para determinar se o Estado cumpriu com suas obrigações de direitos humanos em contextos pós-ditadura (PASQUALUCCI, 2013).

$\mathrm{Na}$ atualidade, a avaliação da atividade estatal é mais complexa no sistema interamericano. Há algumas décadas, os Estados da região ou não tomavam medidas para enfrentar as violações ou não litigavam sobre esse tema perante o SIDH. Hoje, pelo contrário, já há uma robusta jurisprudência da Corte $\operatorname{IDH}^{1}$ que busca estabelecer diretrizes e parâmetros para determinar se as medidas adotadas pelos Estados para enfrentar as violações de regimes passados são oportunas, suficientes e pertinentes.

A Argentina é tida como exemplo na região por ter sido o primeiro país da América Latina a derrubar legislação doméstica que protegia perpetradores de graves violações de direitos humanos ao longo do período de ditadura. De acordo com Emgstrom e Pereira, o ativismo de direitos humanos através de cortes nacionais e internacionais (incluindo a Corte IDH), reforçado pelo apoio do governo de Kirchner, impulsionaram o processo político e judicial que levou à derrubada dos perdões e leis de impunidade (ENGSTROM; PEREIRA, 2012).

Ao longo do desenvolvimento da sua jurisprudência, a Corte IDH sustentou a existência do dever de investigar, julgar e sancionar as violações aos direitos humanos reconhecidos pela CADH. Desde o caso Velásquez Rodriguez vs. Honduras, a Corte foi enfática em determinar que tal dever surge do dever geral de garantia dos direitos humanos, previsto no art. 1.1 da CADH. Vem postulando também uma interpretação sistemática que conjugue o dever geral de garantia ao direito a um recurso judicial efetivo (art. 25 da $\mathrm{CADH}$ ), bem como às regras de devido processo (art. $8^{\circ} \mathrm{da} \mathrm{CADH}$ )

\footnotetext{
${ }^{1}$ Podem-se citar por exemplo os casos: Velásquez Rodriguez vs. Honduras, Barrios Altos vs. Peru, Almonacid Arellano e outros vs. Chile, La Cantuta vs. Peru, Gomes Lund e outros vs. Brasil, Gelmán vs. Uruguai, Contreras e outros vs. El Salvador, Massacres de El Mozote e Lugares Vizinhos vs. El Salvador, Gudiel Álvarez e outros vs. Guatemala.
} 
gera a obrigação estatal de garantir o acesso efetivo à administração da justiça assim como a um recurso rápido e simples que logre que os responsáveis pelas violações aos direitos humanos sejam julgados e que uma reparação pelos danos sofridos seja conquistada (CORTE INTERAMERICANA DE DIREITOS HUMANOS, 1987, 1998a).

O mencionado dever se coloca aos Estados nos casos em que a violação de direitos humanos ultrapassa um determinado umbral de gravidade. No sistema interamericano, há três instrumentos que contemplam expressamente o dever de investigar, julgar e sancionar frente a casos de desaparecimento forçado, tortura e violência contra a mulher, que são considerados graves violações de direitos humanos ${ }^{2}$. Tais situações não são taxativas, haja vista que outras condutas podem ser consideradas como graves violações de direitos humanos, sendo esse um ponto em aberto na jurisprudência do SIDH. No caso Barrios Altos vs. Peru, por exemplo, a Corte reconheceu que execuções extrajudiciais, sumárias ou arbitrárias cometidas por agentes estatais são graves violações de direitos humanos (CORTE INTERAMERICANA DE DIREITOS HUMANOS, 2001).

Perfilando uma análise compreensiva da jurisprudência do SIDH, é possível estabelecer algumas características do dever de investigar, julgar e sancionar: tem como fonte os artigos $1^{\circ}, 8^{\circ}$ e 25 da $\mathrm{CADH}$; predica-se sobre as violações de direitos humanos que ultrapassem o umbral de gravidade; é uma obrigação de meios, considerada cumprida quando o Estado realiza as diligências devidas no sentido de investigar e punir tais violações; implica a necessidade de sanção aos violadores, ainda que não haja a definição de qual seja a sanção apropriada para cada caso. Diante desse panorama, resta a questão sobre se anistias são compatíveis com esse dever e em que condições.

Em diversas situações, a Corte IDH apoiou a tese de que a concessão de autoanistias ou anistias gerais e incondicionadas constitui uma violação ao dever de investigar, julgar e sancionar. Para a Corte, a impunidade pode ser definida como:

\footnotetext{
A falta em seu conjunto de investigação, perseguição, captura, julgamento e condenação dos responsáveis pelas violações de direitos protegidos pela Convenção Americana, toda vez que o Estado tem o dever de combater tal situação por todos os meios legais disponíveis já que a impunidade propicia a repetição crônica das violações de direitos humanos e a total falta de defesa das vítimas e seus familiares (CORTE INTERAMERICANA DE DIREITOS HUMANOS, 1998b).
}

2 Art. $2^{\circ}$ da Convenção Interamericana sobre Desaparecimento Forçado de Pessoas; art. $3^{\circ}$ da Convenção Interamericana para Prevenir e Sancionar a Tortura; art. $1^{\circ}$ da Convenção de Belém do Pará (OEA, 1985, 1994a, 1994b). 
No caso Barrios Altos vs. Peru, que tratava das leis de anistia proferidas pelo Estado Peruano em 1995, a Corte dispôs serem inadmissíveis as disposições de anistia, de prescrição ou o estabelecimento de excludentes de responsabilidade que pretendam impedir a investigação e sanção dos responsáveis das violações graves de direitos humanos (no caso, as forças armadas e policiais). Tais medidas foram consideradas como uma forma de autoanistia e seriam proibidas por atacarem direitos inderrogáveis reconhecidos pelo Direito Internacional dos Direitos Humanos (CORTE INTERAMERICANA DE DIREITOS HUMANOS, 2001).

A Corte não aprovou autoanistias mesmo quando referendadas democraticamente pela maioria significativa de cidadãos através de consultas populares. No caso Gelman vs. Uruguai, a Corte manifestou que:

A existência de um regime democrático está determinada por suas características tanto formais quanto substanciais, pelo que, particularmente em casos de graves violações às normas do Direito Internacional dos Direitos Humanos, a proteção de tais direitos constitui um limite infranqueável à regra das maiorias, é dizer, à esfera do que é suscetível de ser decidido por parte das maiorias em instâncias democráticas (CORTE INTERAMERICANA DE DIREITOS HUMANOS, 2011).

Ademais, a Corte IDH ampliou o espectro da sua proibição, uma vez que não apenas condena o outorgamento das chamadas autoanistias, senão que também aquelas anistias gerais e incondicionadas. No caso brasileiro, por exemplo, no qual se outorgaram anistia em 1979 a todos os atores que perpetraram violações no marco da ditadura militar, a Corte precisou que a incompatibilidade com a $\mathrm{CADH}$ abrange não apenas as autoanistias, mas às anistias aos perpetradores de graves violações de direitos humanos em geral (CORTE INTERAMERICANA DE DIREITOS HUMANOS, 2010).

Os mencionados casos indicam uma orientação da jurisprudência no sentido de que anistias gerais e autoanistias não são toleradas no SIDH. Contudo, todos esses casos tratam de transições de ditaduras para regimes democráticos. Surge, então, uma questão ainda não estabelecida com precisão pela Corte: como considerar as anistias (e outras medidas de perdão a perpetradores) em casos de transição do conflito para a paz?

No caso Massacres de El Mozote vs. El Salvador, a Corte examinou, em um caso ainda sem precedentes, a compatibilidade de leis de anistia expedidas em situações de transição de conflito armado à paz negociada com a CADH. Nessa situação, a Corte recorreu ao estudo do Protocolo II Adicional às Convenções de Genebra de 1949 e às normas do Direito Internacional Humanitário, bem como ao próprio acordo de paz, a 
fim de examinar a compatibilidade das anistias que surgiram das negociações de paz em El Salvador (CORTE INTERAMERICANA DE DIREITOS HUMANOS, 2012).

Ao levar em consideração o acordo de paz, a jurisprudência reconheceu implicitamente certa margem de manobra aos Estados na definição dos instrumentos necessários para assegurar a paz. Considerou também que a lógica do processo político que se materializou nos acordos de paz impunha o dever de investigar e sancionar "ao menos as graves violações de direitos humanos estabelecidas pela Comissão da Verdade, de modo que estas não restassem impunes e se evitara sua repetição" (CORTE INTERAMERICANA DE DIREITOS HUMANOS, 2012).

Quanto à proibição de anistias em âmbito interamericano, a Corte enfatizou que tal norma não é absoluta, especialmente em casos de transição de conflitos armados, à luz do art. 6.5 do Protocolo II Adicional às Convenções de Genebra de 1949, aplicável aos conflitos armados internos:

5 - Quando da cessação das hostilidades, as autoridades no poder procurarão conceder a mais ampla anistia às pessoas que tiverem tomado parte no conflito armado ou que tiverem estado privadas de liberdade por motivos relacionados com o conflito armado, quer estejam internadas, quer detidas (ONU, 1949).

Segundo o juiz Eduardo Ferrer McGregor, esse caso confirma a possibilidade de se conceder anistias amplas a quem, no marco de um conflito armado interno, não tenha incorrido em fatos que se enquadrem como crimes de guerra ou contra a humanidade (MAC-GREGOR, 2014). Ainda assim, esse é um tema que ainda está em estágio incipiente na Corte e demanda intepretações complementares, a fim de que os parâmetros da justiça de transição em casos de conflito armado e construção da paz sejam devidamente estabelecidos.

\section{A transição na Colômbia: tensionamentos entre a justiça, a paz e o risco de impunidade}

De acordo com o relatório mais recente da ONG internacional Human Rights Watch, a violência associada ao conflito armado interno na Colômbia já deslocou forçadamente mais de 6,8 milhões de colombianos, gerando a segunda maior população de deslocados internos no mundo, depois apenas da Síria. Civis na Colômbia continuam a sofrer sérios abusos perpetrados por guerrilhas, bem como por grupos armados sucessores dos paramilitares, os quais emergiram após um processo oficial de desmobilização ocorrido há uma década. Defensores de direitos humanos, líderes sindicais, jornalistas, indígenas, Afrocolombianos e outros ativistas enfrentam ameaças 
de morte e violência, mas os perpetradores raramente são responsabilizados (HUMAN RIGHTS WATCH, 2016a).

$\mathrm{Na}$ atualidade, para entender a situação humanitária na Colômbia, é preciso compreender a dificuldade de executar políticas de pós-conflito num cenário sociopolítico em que o conflito ainda não terminou. O governo da Colômbia e as FARC têm se engajado em negociações de paz em Cuba desde 2012, e até janeiro de 2016, haviam chegado a um acordo sobre quatro dentre os seis itens na agenda de negociação.

Em relatório de 2013, o ONG International Crisis Group já delineava parâmetros que a justiça de transição na Colômbia deveria atender a fim de que se adequasse às exigências do Direito Internacional dos Direitos Humanos e Humanitário. Destacava então a ONG que a justiça para as vítimas de todas as partes do conflito, incluindo vítimas de agentes estatais, é parte essencial de qualquer regime viável de justiça de transição. Os principais responsáveis pelos crimes mais graves, de qualquer lado, devem ser processados e penas adequadas devem ser impostas (INTERNATIONAL CRISIS GROUP, 2013).

Seria admissível a determinação de anistia para cobrir os crimes políticos ou correlatos das FARC, mas nunca abrangendo crimes contra a humanidade ou crimes de guerra. Membros das FARC fora das categorias mais responsáveis devem ser elegíveis a um processo administrativo que, sob as condições relacionadas à reconciliação, garanta-os a possibilidade de suspensão ou redução de sentenças, caso sejam condenados por crimes relacionados ao conflito fora do escopo da anistia (INTERNATIONAL CRISIS GROUP, 2013).

Em junho de 2015, o governo e as FARC concordaram com a criação de uma Comissão da Verdade a fim de conduzir investigações não judiciais sobre graves violações de direitos humanos e sérias violações do Direito Internacional Humanitário durante o conflito (HUMAN RIGHTS WATCH, 2016a).

Em setembro de 2015, o governo e as FARC anunciaram um acordo que criaria uma nova "Jurisdição Especial de Paz" (JEP) para processar os responsáveis por graves violações de direitos humanos cometidas durante o conflito. Segundo o acordo, firmado em 15 de dezembro de 2015, a Jurisdição Especial de Paz constituir-se-á por uma série de salas de justiça, entre as quais se incluem a Sala de Anistia e Indulto, e um Tribunal para a Paz, que terá como objetivo primordial investigar, esclarecer, processar e sancionar as graves violações de direitos humanos e as sérias infrações ao Direito Internacional Humanitário (ALTO COMISIONADO PARA LA PAZ DE 
COLOMBIA, 2015). Nos termos do mencionado acordo, as seguintes disposições referem-se diretamente ao tema das anistias e perdão:

23.- À finalização das hostilidades, de acordo com o Direito Internacional Humanitário, o Estado colombiano pode outorgar a anistia "mais ampla possível" aos rebeldes que pertençam a organizações que hajam subscrito um acordo final de paz (grifo meu), segundo o estabelecido no numeral 10 , assim como àquelas pessoas que tenham sido acusadas ou condenadas por delitos políticos ou conexos mediante providências proferidas pela justiça, outorgar-se-á a anistia mais ampla possível, respeitando o estabelecido a respeito do presente documento [...].

24.- A Constituição permite outorgar anistias ou indultos pelo delito de rebelião e outros delitos políticos conexos.

25.- Há delitos que não são anistiáveis nem indultáveis em conformidade com os numerais 40 e 41 deste documento. Não se permite anistiar os crimes de lesa humanidade, nem outros crimes definidos no Estatuto de Roma (grifo meu).

26.- É necessário determinar claramente quais são os delitos que são anistiáveis ou indultáveis e aqueles que não o são, para efeitos de segurança jurídica. A tal fim, as normas de anistia que se adotem respeitarão os princípios estabelecidos no presente documento de criação da JEP. No momento de determinar as condutas anistiáveis ou indultáveis, aplicar-se-á o princípio de favorabilidade para o destinatário da anistia ou indulto, quando não exista no Direito Internacional uma proibição de anistia ou indulto a respeito das condutas de que se haja acusado aos rebeldes ou a outras pessoas acusadas como tal. O princípio da favorabilidade aplicar-seá a todos os destinatários da JEP.

27.- A concessão de anistias ou indultos ou o acesso a qualquer tratamento especial, não exime do dever de contribuir, individual ou coletivamente, ao esclarecimento da verdade conforme ao estabelecido neste documento.

28.- O grau de contribuição voluntária de cada pessoa ou coletivo à verdade estará em relação com o tratamento a ser recebido no componente da justiça. 29.- Determinar-se-á de maneira clara 0 alcance de cada um dos delitos que não são anistiáveis e dos que o são para efeitos de segurança jurídica (grifo meu) (ALTO COMISIONADO PARA LA PAZ DE COLOMBIA, 2015, tradução minha).

Por outro lado, aqueles que demorarem a aceitar a responsabilidade por suas irregularidades acabariam por servir o mesmo tempo, mas em prisões comuns, enquanto que aqueles que não cooperarem poderiam eventualmente ser condenados e punidos com pena de prisão de até 20 anos (INTERNATIONAL CRISIS GROUP, 2015).

De acordo com o ICG, as FARC cederam mais do que antes ao aceitar o requerimento de que os mais responsáveis pelos crimes sérios devem sofrer restrições em suas liberdades por até oito anos. O governo, por outro lado, aceitou que o novo mecanismo tenha jurisdição sobre todos que participaram do conflito interno armado incluindo agentes estatais (INTERNATIONAL CRISIS GROUP, 2015).

Dos delineamentos gerais do acordo quanto à questão da anistia e perdão, trazidos acima, é possível extrair algumas observações, como a importância que os 
parâmetros de Direito Internacional de Direitos Humanos têm para o vindouro detalhamento das normas aplicáveis no marco da JEP.

Os resultados do acordo de paz ora em negociação têm dividido opiniões inclusive entre importantes instituições de direitos humanos. Por um lado, a ONU, seja por meio do Alto Comissariado das Nações Unidas para Direitos Humanos ou pelo Conselho de Segurança, têm se pronunciado a favor do acordo. O Conselho de Segurança, por exemplo, em 2016, salientou seu inteiro comprometimento com o processo de paz na Colômbia e aplaudiu o compromisso tanto das FARC quanto do governo colombiano em alcançar um cenário de paz (CONSELHO DE SEGURANÇA DA ONU, 2016).

De forma mais específica, o Alto Comissariado para Direitos Humanos da ONU reconhece que o componente de justiça do acordo de paz gerou um amplo debate e foi o foco de setores críticos ao processo de paz, uma vez que a Jurisdição Especial para a Paz prevê mecanismos de anistia e perdão, assim como um procedimento judicial especial para crimes graves não cobertos pelas anistias. De acordo com o Alto Comissariado, a Jurisdição Especial oferece uma oportunidade contra a impunidade, já que o acordo ainda é muito amplo e sua implementação requererá maior definição, inclusive sobre os atos específicos a serem processados, o marco legal aplicável e procedimentos para orientação estratégica (CONSELHO DE DIREITOS HUMANOS DA ONU, 2016).

No mesmo sentido, a ONG ICG tem afirmado que "o acordo sobre justiça de transição é firme, eficiente e um inteligente passo adiante. Se implementado corretamente, aumenta de forma significativa as chances de que um dos conflitos mais antigos do mundo chegue ao fim" (INTERNATIONAL CRISIS GROUP, 2015).

De acordo com o ICG, ao oferecer anistia por crimes políticos e crimes associados, o acordo resolve as incertezas legais de milhares de guerrilheiros. Simultaneamente, ao reafirmar que certos crimes (crimes contra a humanidade, genocídio e graves crimes de guerra) não são passíveis de anistia e os seus perpetradores serão processados, satisfazendo assim, as obrigações internacionais da Colômbia frente o Direito Internacional, e assegura uma passagem mais fácil para um acordo de paz definitivo, apesar da possibilidade de algumas revisões, pelo legislativo, a Corte Constitucional e outros mecanismos (INTERNATIONAL CRISIS GROUP, 2015).

Por outro lado, a ONG Human Rights Watch tem sido vocal quanto ao risco de que o acordo de paz leve à impunidade tanto das FARC como de agentes estatais. De 
acordo com comunicado de 21 de dezembro de 2015, a ONG alerta que o acordo assegurará que os responsáveis pelas atrocidades de ambos os lados do conflito escaparão de uma punição significativa (HUMAN RIGHTS WATCH, 2015).

A ONG critica o fato de que, segundo o referido acordo, os responsáveis por crimes contra a humanidade e sérios crimes de guerra que cooperassem com o novo sistema judicial e confessassem seus crimes poderiam passar de cinco a oito anos em "restrição efetiva de liberdade" mas não encarar nenhum tempo de prisão (HUMAN RIGHTS WATCH, 2016a).

Ademais, observa que o acordo está repleto de referências abstratas à justiça, responsabilização e à necessidade de restringir a liberdade dos perpetradores, mas um olhar mais rigoroso ao texto permite entrever uma série de brechas legais, ambiguidades e omissões que fazem com que tais referências pareçam, na melhor das hipóteses, uma promessa vazia. Argumenta também que nenhum tribunal internacional permitiu que criminosos de guerra condenados evadissem a prisão para esses tipos de graves crimes. Recomenda, por fim, que a Corte Constitucional da Colômbia, bem como o Tribunal Penal Internacional (TPI) deveriam revisar cuidadosamente o acordo a fim de assegurar que todas as vítimas recebam a justiça que elas merecem (HUMAN RIGHTS WATCH, 2015).

Um outro ponto mais específico de preocupação declarado pela ONG Human Rights Watch diz respeito à possibilidade de que, no marco do acordo, os oficiais responsáveis pelo escândalo dos "falsos positivos" escapem à justiça, uma vez que o processamento desses casos ficaria a cargo da JEP. A preocupação manifestada pela HRW concentra-se principalmente na perspectiva de que o acordo pode dispensar certos casos de serem processados. Outros processos podem ser interpretados de forma a estreitar o âmbito da responsabilidade de comandantes por atos de seus subordinados. Pessoas condenadas pela JEP podem não chegar a cumprir nenhum tempo de prisão. Ademais, aqueles já condenados pela justiça comum podem ser liberados (HUMAN RIGHTS WATCH, 2016).

\footnotetext{
3 Entre 2002 e 2008, brigadas do Exército em toda a Colômbia sistematicamente executaram mais de 3 mil civis a fim de aparentar que estavam vencendo guerrilheiros em combate, escândalo que ficou conhecido no país como "falsos positivos" (HUMAN RIGHTS WATCH, 2015). Sobre as investigações decorrentes dos "falsos positivos", observe-se que uma emenda constitucional de 2012 permite que o julgamento de assassinatos de civis por militares seja realizado por tribunais militares ao invés de tribunais civis. O problema é que tribunais militares têm falhado em responsabilizar e punir agressores, o que tem também levantado o argumento da impunidade (HUMAN RIGHTS WATCH, 2014).
} 
É importante perceber que as divergências no posicionamento de diversas instituições de direitos humanos refletem o difícil equilíbrio entre os valores da paz e da justiça, tão profusamente proclamados no acordo entre o governo colombiano e as FARC.

Além disso, não é a primeira vez que esse debate tem sido levantado no tocante à situação da Colômbia, haja vista que, além das negociações de paz com as FARC, o governo colombiano vem implementando políticas pós-conflito desde 2002, o que se refletiu em um agravamento da situação humanitária em muitos aspectos.

A primeira dessas iniciativas foi a Lei 975 de 2005 (Lei de Justiça e Paz), um marco jurídico para a desmobilização dos grupos paramilitares. A legislação foi reforçada com a ação da Agência Colombiana para a Reintegração (ACR), criada em 2003 e encarregada de coordenar, assessorar e implementar a reintegração social e econômica dos desmobilizados. Desde a primeira leva de desmobilização, os meios de comunicação registraram casos de desmobilizados executados pelos grupos armados restantes que não acolheram a anistia (INTERNATIONAL CRISIS GROUP, 2013).

Outra das iniciativas pós-conflito foi a Lei 1.448 de 2011 ou Lei de Reparação às Vítimas e Restituição de Terras, a qual visa atender, assistir e reparar integralmente as vítimas do conflito armado. Com a Lei 1.448, foram criadas a 'Unidad de Atención y Reparación Integral a las Víctimas' (UARIV), e a 'Unidad de Restitución de Tierras' (URT). Da mesma forma, a criação de associações de vítimas no marco da lei ocasionou manifestações de violência, ameaças, assassinatos e perseguições contra líderes de tais associações (INTERNATIONAL CRIS IS GROUP, 2013).

Em julho de 2012, o governo promulgou a emenda constitucional do Regime Jurídico para a Paz, que foi criticada por gerar impunidade com relação a atrocidades cometidas por guerrilhas, paramilitares e o exército. A emenda permite que o congresso limite a punição apenas aos indivíduos considerados "mais responsáveis" pelas atrocidades cometidas por grupos armados e prevê imunidade para aqueles que planejaram, executaram e cobriram os mesmos crimes, mas não são considerados “os mais responsáveis", termo que a emenda não define. Ademais, essa emenda concede autoridade ao congresso para eximir de investigações criminais casos como estupros e desaparecimentos forçados - se não forem parte de um ataque sistêmico (HUMAN RIGHTS WATCH, 2014).

Saliente-se, por outro lado, que tampouco será a última vez que esse debate quanto à prevalência da paz ou da justiça será travado à luz do contexto colombiano. 
Além das incertezas sobre o que reserva o acordo de paz entre o governo e as FARC, anunciaram-se, em 31 de março de 2016, as primeiras negociações de paz oficiais entre o governo colombiano e o grupo armado Exército de Libertação Nacional (ELN) ${ }^{4}$ (INTERNATIONAL CRISIS GROUP, 2016). Com efeito, o governo colombiano tem sido pressionado para conseguir um acordo com ambos os grupos, visto que a incapacidade de se alcançar um acordo de paz com o ELN poderia dificultar de forma significativa a implementação de um acordo com as FARC (INTERNATIONAL CRISIS GROUP, 2014).

\section{Conclusões}

Nas últimas décadas, o termo "justiça de transição" ganhou espaço no campo teórico e prático dos direitos humanos. O dever estatal de investigar, processar e punir graves violações de direitos humanos é previsto na Convenção Americana de Direitos Humanos (CADH), por meio da interpretação conjunta dos artigos $1^{\circ}, 2^{\circ}, 8^{\circ}$ e 25 . O escopo e o conteúdo de tal dever em contextos de transição vêm sendo consolidado por julgados e pareceres do SIDH. A maior parte das decisões diz respeito a casos de transição de um regime autoritário para um democrático.

Contudo, o conteúdo de tal obrigação em contextos de transição do conflito armado interno para a paz negociada ainda está sujeito a debates, especialmente no que tange a questões como a possibilidade da concessão de anistias. Esse tópico traz à tona a tensão previamente explorada entre o valor da paz e da justiça. Como compatibilizar esses dois valores à luz dos direitos humanos?

Em uma das únicas decisões em que a Corte IDH se debruçou sobre o tema, qual seja, El Mozote vs. El Salvador, definiu-se que a vedação de anistias não era

\footnotetext{
${ }^{4}$ O Exército de Liberação Nacional (ELN) surge em 1962 quase em paralelo com a fundação das FARC. De forma similar ao Exército Popular de Liberação - EPL, fundado em 1967, sua história remete ao encontro entre os jovens urbanos colombianos formados e radicalizados conforme as diretrizes das revoluções cubana e chinesa, e os herdeiros das antigas guerrilhas. Desde o começo dos anos 2000, o ELN perdeu considerável força militar. O grupo é consideravelmente menor que as FARC, e seu declínio está relacionado à expansão paramilitar desde a metade dos anos 1990, que forçaram o ELN a instalarse em zonas mais isoladas e menos populosas. Na falta de capacidade para operações ofensivas maiores, o ELN se focou em sabotagens e extorsões, recorrendo ao uso de minas explosivas. O grupo também é responsável por sequestros, assassinatos e bombardeios, além de intimidar juízes, promotores e testemunhas. Desde 2009, o grupo tem buscado uma recuperação, com um lento crescimento de ataques e combatentes. Muitas das operações do ELN são direcionadas a infraestruturas petrolíferas e contra trabalhadores, que são alvos de sequestro (GRUPO DE MEMORIA HISTÓRICA, 2013; INTERNATIONAL CRISIS GROUP, 2014).
} 
absoluta, uma vez que seria necessário levar em consideração os termos do acordo de paz. A Corte indicou, assim, que as anistias em casos de transição para a paz apenas seriam inadmissíveis quando se tratasse de crimes de guerra ou contra a humanidade, levando em consideração critérios do Direito Internacional Humanitário.

Caberia ainda questionar se tal interpretação é justa e adequada ou se, pelo contrário, não reforçaria o binarismo entre paz e justiça. O caso da Colômbia ilustra de forma evidente essa tensão. Como foi brevemente elucidado no presente trabalho, a linha de equilíbrio entre justiça e paz é muito tênue e o risco de impunidade é significativo.

Nesse sentido, trata-se de um tema que ainda merece interpretações e investigações mais profundas, principalmente à luz dos diversos conflitos armados que assolaram e ainda assolam a região das Américas, a fim de que o sistema regional de proteção aos direitos humanos consiga cumprir adequadamente seus objetivos de reparação, paz e justiça.

\section{Referências}

ALTO COMISIONADO PARA LA PAZ DE COLOMBIA. Acuerdo sobre las Víctimas del Conflicto: "Sistema Integral de Verdad, Justicia, Reparación y No Repetición", incluyendo la Jurisdicción Especial para la Paz; y Compromiso sobre Derechos Humanos. Disponível em:

$<$ http://www.altocomisionadoparalapaz.gov.co/procesos-y-conversaciones/proceso- depaz-con-las-farc-ep/documentos-y-comunicados-conjuntos/Documents/acuerdovictimas.pdf>. Acesso em: 30 mar. 2016.

CLARK, P.; PALMER, N. Challenging Transitional Justice. London: The Dickson Poon School of Law, King's College London, 2016.

COMISSÃO INTERAMERICANA DE DIREITOS HUMANOS. Informe de país. Colombia: Verdad, justicia y reparación. San José: [s.n.].

CORTE INTERAMERICANA DE DIREITOS HUMANOS. Caso Velásquez Rodríguez Vs. Honduras. Sentencia de 26 de junio de 1987. Excepciones Preliminares., 1987. Disponível em:

<http://www.corteidh.or.cr/docs/casos/articulos/seriec_01_esp.pdf>

CORTE INTERAMERICANA DE DIREITOS HUMANOS. Caso Loayza Tamayo Vs. Perú. Sentencia de 27 de noviembre de 1998. Serie C, No 42, 1998a. Disponível em: <http://www.corteidh.or.cr/docs/casos/articulos/seriec_42_esp.pdf>

CORTE INTERAMERICANA DE DIREITOS HUMANOS. Caso Panigua Morales y otros vs. Guatemala. Fondo. Sentencia del 8 de marzo de 1998. Serie C No. 37, 1998b. Disponível em: <http://www.corteidh.or.cr/docs/casos/articulos/Seriec_76_esp.pdf> 
CORTE INTERAMERICANA DE DIREITOS HUMANOS. Caso Barrios Altos vs. Peru. Fondo. Sentencia de 14 de marzo de 2001, Serie C, No 75, 2001. Disponível em: http://www.corteidh.or.cr/docs/casos/articulos/Seriec_75_esp.pdf

CORTE INTERAMERICANA DE DIREITOS HUMANOS. Caso Gomes Lund e outros (Guerrilha do Araguaia) vs. Brasil. Sentencia de 24 de noviembre de 2010. Excepciones Preliminares, Fondo, Reparaciones y Costas. Serie C, No. 219, 2010.

Disponível em: <http://www.corteidh.or.cr/docs/casos/articulos/seriec_219_por.pdf> CORTE INTERAMERICANA DE DIREITOS HUMANOS. Caso Gelman vs. Uruguai. Fondo y Reparaciones. Sentencia de 24 de febrero de 2011, Serie C, No 221, 2011. Disponível em: <http://www.corteidh.or.cr/docs/casos/articulos/seriec_221_esp1.pdf>

CORTE INTERAMERICANA DE DIREITOS HUMANOS. Caso Masacres de El Mozote y lugares aledaños vs. El Salvador. Sentencia de 25 de octubre de 2012.

Fondo, Reparaciones y Costas. Serie C, No. 252, 2012. Disponível em: <http://www.corteidh.or.cr/docs/casos/articulos/seriec_252_esp.pdf>

DE BAETS, A. The Impact of the Universal Declaration of Human Rights on the Study of History. History and Theory, v. 48, p. 20-43, 2009.

ENGSTROM, P.; PEREIRA, G. From Amnesty to Accountability: The Ebb and Flow in the Search for Justice in Argentina. In: LESSA, F.; PAYNE, L. (Eds.). . Amnesty in the Age of Human Rights Accountability - Comparative and International Perspectives. Cambridge: Cambridge University Press, 2012. p. 97-122.

GRUPO DE MEMORIA HISTÓRICA. ¡BASTA YA! Colombia: Memorias de guerra y dignidad. Bogotá: Imprenta Nacional, 2013.

HUMAN RIGHTS WATCH. World Report 2014 - Colombia. Disponível em: <http://www.refworld.org/docid/52dfddf412.html>. Acesso em: 30 mar. 2016.

HUMAN RIGHTS WATCH. Colombia: Agreeing to Impunity. Disponível em: <http://www.refworld.org/country,,,,COL,,569560151bb,0.html>. Acesso em: 30 mar. 2016.

HUMAN RIGHTS WATCH. Colombia: FARC Pact Risks Impunity for "FalsePositives". Disponível em: <http://www.refworld.org/country,,,,COL,,56fa2ff94,0.html>. Acesso em: 30 mar. 2016.

INTERNATIONAL CRISIS GROUP. Transitional Justice and Colombia's Peace Talks. Disponível em: <http://www.refworld.org/cgibin/texis/vtx/rwmain?page $=$ search \&docid $=522054724 \&$ skip $=0 \&$ query $=$ transitional justice\&coi=COL> . Acesso em: 30 mar. 2016.

INTERNATIONAL CRISIS GROUP. Left in the Cold? The ELN and Colombia's Peace Talks. Disponível em: <http://www.refworld.org/docid/530ef01a4.html>. Acesso em: 31 mar. 2016. 
INTERNATIONAL CRISIS GROUP. Statement on the Transitional Justice Agreement between the Colombian Government and the FARC. Disponível em: $<$ http://www.refworld.org/cgibin/texis/vtx/rwmain?page $=$ search\&docid $=560507604 \&$ skip $=0 \& q u e r y=$ transitional justice\&coi=COL>. Acesso em: 30 mar. 2016.

INTERNATIONAL CRISIS GROUP. The Colombian Government's First Official Peace Talks with the ELN. Disponível em: <http://www.crisisgroup.org/en/publication-type/statements/the-colombiangovernment-s-first-official-peace-talks-with-the-eln.aspx>. Acesso em: 31 mar. 2016.

LEEBAW, B. A. The Irreconcilable Goals of Transitional Justice. Human Rights Quarterly, v. 30, n. 1, p. 95-118, 2008.

MAC-GREGOR, E. F. Las siete principals líneas jurisprudenciales de la Corte Interamericana de Derechos Humanos aplicable a la justicia penal. Revista IIDH, v. 59, p. 29-118, 2014.

NAGY, R. Transitional Justice as Global Project: critical reflections. Third World Quarterly, v. 29, n. 2, p. 275-289, 2008.

OEA. Convenção Interamericana para Prevenir e Sancionar a Tortura de 1985. Disponível em: <http://www.pge.sp.gov.br/centrodeestudos/bibliotecavirtual/instrumentos/cartagena. htm>. Acesso em: 30 mar. 2016.

OEA. Convenção Interamericana para Prevenir, Punir e Erradicar a Violência contra a Mulher, "Convenção de Belém do Pará" de 1994. Disponível em: <http://www.cidh.org/Basicos/Portugues/m.Belem.do.Para.htm>. Acesso em: 30 mar. 2016a.

OEA. Convenção Interamericana sobre Desaparecimento Forçado de Pessoas de 1994. Disponível em: <http://www.cidh.org/Basicos/Portugues/k.Desaparecimento.htm>. Acesso em: 30 mar. $2016 b$.

ONU. Protocolo II Adicional às Convenções de Genebra de 12 de Agosto de 1949 relativo à Proteção das Vítimas dos Conflitos Armados Não Internacionais. Disponível em: <http://www.gddc.pt/direitos-humanos/textos-internacionaisdh/tidhuniversais/dih-prot-II-conv-genebra-12-08-1949.html>. Acesso em: 30 mar. 2016.

PASQUALUCCI, J. M. The Practice and Procedure of the Inter-American Court of Human Rights. Cambridge: Cambridge University Press, 2013.

SALMÓN, E. Algumas reflexões sobre o Direito Internacional Humanitário e a Justiça Transicional: Lições da experiência latino-americana. In: REÁTEGUI, F. (Ed.). . 
Justiça de Transição: manual para a América Latina. Brasília: Ministério da Justiça, 2011. p. 227-262.

VAN ZYL, P. Promovendo a Justiça Transicional em sociedades pós-conflito. In: REÁTEGUI, F. (Ed.). . Justiça de Transição: Manual para a América Latina. Brasília: Ministério da Justiça, 2011. p. 47-72. 